\title{
0 marxismo heterodoxo de João Bernardo
}

\author{
João Alberto da Costa Pinto ${ }^{1}$
}

Meu propósito neste colóquio é o de fazer uma rápida apresentação de alguns aspectos conceituais que considero fundamentais na proposta teórica de João Bernardo, pensador marxista português, autor de uma obra que vem sendo elaborada ao longo das últimas três décadas e que já reúne, além de inúmeros ensaios e artigos em revistas especializadas, um total de onze livros publicados em Portugal e no Brasil, alguns com tradução integral e parcial para o francês e o espanhol. Apesar desse significativo conjunto de obra, ainda assim, João Bernardo é quase que um autor desconhecido no Brasil.

João Bernardo nasceu no ano de 1946. Aos 19 anos participou de organizações comunistas clandestinas onde manifestou oposição radical à ditadura civil de Oliveira Salazar. Por causa de sua militância política foi-lhe negado o acesso a quaisquer das universidades portuguesas. Em 1965, exilou-se na França. Em Paris, encontrou grande movimentação política. Juntou-se a agremiações maoístas e freqüentou alguns cursos de Louis Althusser. Suas inquietações intelectuais resolviam-se pelo autodidatismo. Explorava as possibilidades do ambiente acadêmico sem, no entanto, dar seqüência como aluno regular. Até hoje, João Bernardo não tem qualquer título universitário; tem apenas um curso secundário. Num contexto de grande agitação política e intelectual, permaneceu na França até 1974. Com a Revolução dos Cravos em 25 de abril de 1974, data que marcou em definitivo a derrocada da ditadura salazarista-marcellista,

1 Prof. Do Departamento de História da Universidade federal de Goiás.

cadernos cemarx, $\mathrm{n}^{0} 2-2005 \mid \mathbf{2 1}$ 
retornou a Portugal. Em Lisboa, fez parte do grupo que fundou o jornal o Combate. Nas lutas sociais posteriores ao 25 de abril, este jornal teve um importante papel na organização do movimento autonomista conselhista dos trabalhadores portugueses. No mesmo período, isto é, nos anos de 1974 e 1975, João Bernardo preparava a publicação (que aconteceu em agosto de 1975) do livro Por uma Teoria do Modo de Produção Comunista. Este livro foi a referência teórica do comunismo conselhista português.

Foi historiando e refletindo conceitualmente sobre as bases societárias das lutas anticapitalistas no seio das experiências socialistas contemporâneas e na própria experiência portuguesa que João Bernardo definiu seu projeto de marxismo centrado no que chama de marxismo das relações de produção, que como programa teórico-prático antepunha-se ao marxismo das forças produtivas, paradigma dos partidos comunistas.

Ao longo da década de 1970, João Bernardo trouxe a público uma série de obras que acabaram por fundamentar teoricamente não só a experiência do conselhismo português, durante a Revolução dos Cravos, como também fundamentaram uma proposta radicalmente heterodoxa às bases do marxismo que lhe era contemporâneo. Nesta comunicação, com a pretensão de apenas fazer uma rápida apreciação introdutória a alguns aspectos do marxismo do autor, estarei considerando, principalmente, aquilo que chamo de a epistemologia da revolução conselhista - apresentando aspectos de sua obra iniciada na década de 1970 e consumada em 1991, com a publicação de Economia dos Conflitos Sociais, sua obra síntese, a melhor exposição do modelo teórico marxista.

No contexto das lutas consiliares portuguesas no período de 1974-1976, o autor afirma sua proposição teórica como circunstância intrínseca de sua trajetória política. O aspecto inovador da sua proposta marxista, diante das lutas que lhe eram contemporâneas, era o de oferecer um plano teórico explicativo distanciado de qualquer premissa apriorística. Um modelo calcado na processualidade das lutas dos trabalhadores portugueses pelo autonomismo conselhista. Sua "tarefa" prática como intelectual era a de desenvolver a explicação teórica com o propósito de conceituar as novas práticas de lutas sociais dos trabalhadores diante do conselhismo autogestionário. É da sua luta política, junto ao coletivo d'O Combate, que se pode observar o nascimento do seu projeto marxista. Seu projeto teórico aponta o esforço de conceituação das novas práticas políticas dos trabalhadores portugueses no processo revolucionário e tal trabalho pode ser sumariado naquilo que define como a Lei do Institucional - o termo teórico do Modo de Produção Comunista. Ou, dizendo de outra maneira: o termo teórico-conceitual antípoda à Lei do Valor - a expressão conceitual do Modo de

22 O marxismo heterodoxo de João Bernardo 
Produção Capitalista. Nas proposições doa autor não há qualquer menção a uma teoria da transição de um modo de produção a outro.

Quanto mais se desenvolverem os conselhos de fábrica como formas de controle e gestão da produção, tanto mais desaparecem os intermediários nesse controle. Ou seja, quanto mais se desenvolver um dos aspectos dos conselhos de fábrica, mais o outro se extingue. É este o sentido do conceito de "estado em extinção". O "Estado em extinção" é o comunismo em constituição ${ }^{2}$.

O que o autor afirma é que das contradições que as práticas dos trabalhadores vão "solucionando", mais distante fica a auto-afirmação hegemônica do capitalismo e mais visível se encontra o novo modo de produção, o modo de produção comunista. Desse modo, no marxismo de João Bernardo inexiste qualquer fase de transição de um modo de produção a outro (neste caso, nota-se, do capitalismo ao comunismo). Os conselhos determinam historicamente o controle social sobre a produção. Os conselhos impõem a extinção do poder com a afirmação do poder político com a afirmação de um novo tipo de poder. "O coletivo social apropria-se dos meios de produção e gere o processo de produção mediante o poder político em extinção ${ }^{3 "}$. Logo, "os conselhos de fábrica são pois, a forma institucional das novas relações de produção ${ }^{4}$. Com as práticas dos conselhos, impõe-se historicamente a lei do novo modo de produção: a Lei do Institucional.

No regime capitalista, o critério de apreciação dos produtos é inerente a esses produtos, uma finalidade que lhes é estabelecida como comum e que a lei do valor regula. No modo de produção comunista, os produtos são produzidos como valores de uso, para empregar o termo que Marx contrapõe à essência dos produtos capitalistas. O critério de produção é, portanto, extrínseco à essência dos produtos, e residirá na lei do institucional 5 .

Com a Lei do Institucional, as possibilidades da revolução estão sempre presentes como negativo do atual modelo produtivo capitalista e essa negatividade é sempre a manifestação concreta da imposição das práticas dos trabalhadores na esfera produtiva. É com a lei do Institucional que o autor caracteriza o marxismo das relações sociais de produção.

João Bernardo parte do suposto de que há uma contradição fundamental na refle$-\ldots-\ldots$

2 João Bernardo, Para uma teoria do modo de produção comunista. Porto, Afrontamento, 1975, p.76. 3 Idem, p.91.

4 Idem, p.93.

5 Idem, p.97.

cadernos cemarx, $n^{0}-2-2005 \mid 23$ 
xão de Marx. A contradição estaria na definição de mercado como a base caracterizadora da totalidade capitalista. No mercado, os produtos/mercadorias aparecem como produtos sociais. O acaso e a livre-concorrência é que estabeleceriam o valor social da mercadoria. O mercado é, portanto, o espaço societário da concorrência intercapitalista. Contudo, no interior da gestão fabril não está presente o acaso e nem o arbitrário da lógica concorrencial do mercado. O interior das unidades produtivas impõe a ordem e o equilíbrio da gestão racionalizada. Ora, se a característica básica do capitalismo é a lógica arbitrária da livre-concorrência, a ultrapassagem revolucionária do capitalismo para o socialismo seria realizada com o controle do mercado por um modelo de gestão similar àquele já desenvolvido nas unidades produtivas capitalistas. Assim, o sistema de organização, as técnicas de gestão, a disciplina da força de trabalho, a tecnologia e a maquinaria - nascidos e criados no interior do capitalismo -, ao serem reordenados com o outro uso político e outro uso social (mercado controlado e disciplinado), forneceriam as bases, o germe do futuro modo de produção ${ }^{6}$. Com essa argumentação, o autor caracteriza o chamado marxismo das forças produtivas. No entanto, o marxismo das forças produtivas é totalmente alheio à questão da mais-valia ${ }^{7}$. E a questão da mais-valia é fundamental para a construção da crítica da economia capitalista. Esta questão fundamental, Marx também desenvolveu n'O Capital. Pra João Bernardo, esse seria um aspecto contraditório presente na teoria marxiana.

A mais-valia é resultado da capacidade que a força de trabalho gasta no processo de produção, capacidade esta que resulta num tempo de trabalho superior àquele que em si incorpora como valor-mercadoria ou, simplificando a definição: "o tempo de trabalho que os trabalhadores são capazes de despender no processo de produção é maior do que o tempo de trabalho que eles incorporam na sua própria força de trabalho ${ }^{8}$. A realização social da força de trabalho apresenta uma intrínseca relação contraditória. Para João Bernardo, a organização do processo produtivo é a organização dessa contradição. Logo, as técnicas de gestão, a disciplina do trabalho, a maquinaria e suas sucessivas renovações tecnológicas têm como função aumentar o tempo do sobretrabalho e reduzir o tempo de trabalho necessário para a manutenção da vida do trabalhador. Assim, a tecnologia (e os seus usos de controle produtivo da força de

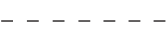

6 João Bernardo, Economia dos conflitos sociais. São Paulo, Cortez, 1991, p.310.

7 Idem, p.311.

8 João Bernardo, Estado - A silenciosa multiplicação do poder. São Paulo, Escrituras, 1998, p.07/08.

240 marxismo heterodoxo de João Bernardo 
trabalho), não é neutra. A tecnologia não é neutra porque é a expressão social da capacidade de expropriação do valor do tempo do trabalho assalariado, assim como a sua "domesticação" estrutural. Definindo-se as formas da expropriação da maisvalia, apresenta-se a base do marxismo das relações sociais de produção. Adiante, será observado como esta "corrente" se manifestará historicamente como antípoda à do marxismo das forças produtivas.

Foi dito anteriormente que o marxismo das forças produtivas estabelece como norte revolucionário a apropriação dos trabalhadores da gestão das formas produtivas capitalistas. A tecnologia, por exemplo, para essa corrente, é vista como simples maquinário. Por não considerar o fato de a tecnologia ser antes de tudo relação social de trabalho, antes de ser simples maquinário, esta corrente, no seu propósito revolucionário, reafirma a mesma capacidade de antes de expropriação da maisvalia. Assim, a revolução acaba por reproduzir a verticalidade da gestão, já que as relações sociais do trabalho permanecem as mesmas. Como afirma João Bernardo, o marxismo das forças produtivas fundamenta o capitalismo de Estado, já que o processo revolucionário limitou-se a estender ao mercado do livre arbítrio os fundamentos organizativos da racionalidade administrativa do espaço produtivo. Não se definem relações sociais de novo tipo. Reproduzem-se societariamente as mesmas formas de poder existentes no capitalismo; a diferença é que esse poder passa a ser controlado institucionalmente pelas representações políticas da classe operária, basicamente os sindicatos e/ou o poder dos partidos comunistas, na experiência histórica do socialismo contemporâneo. Nessa situação, a classe operária não encontra apenas a burguesia como antagonista, mas também os gestores (dos sindicatos, do partido e das empresas estatais).

A corrente do marxismo das relações sociais de produção manifesta-se radicalmente contrária a todas as instituições de poder capitalista. Assim, historicamente não poderia aceitar qualquer forma planificada de gestão da economia como prática de socialismo. Não é à toa, portanto, que apresentou crítica radical aos bolcheviques e à direção do socialismo soviético (como exemplo de tal assertiva, temos as históricas intervenções, na década de 1920, de Karl Korsch, Hermann Gorter, Anton Pannekoek, entre outros). A única possibilidade de se evitar a extorsão da mais-valia no universo produtivo estaria na realização de novas formas de sociabilidade do trabalho. E estas passariam pela recusa radical de qualquer hierarquização do controle da produção. O controle da produção seria decidido pela prática autogestionária, e tal prática, ao se disseminar pelo todo social, implicaria no desaparecimento das institui-

cadernos cemarx, $n^{0}-2-2005 \mid 25$ 
ções formais de poder, não importa de que tipo sejam, se capitalistas ou socialistas (segundo o modelo soviético).

Para esta corrente, portanto, a revolução está presente como negativo imediato do atual modelo produtivo capitalista; negatividade potencializada pela redefinição das práticas dos trabalhadores na esfera produtiva, isto é, a realização da Lei do Institucional.

Pelas limitações do espaço, outros aspectos da proposta marxista de João Bernardo foram aqui deixados de lado. No entanto, é necessário afirmar que - ainda mais porque é uma obra em gestação - as assertivas do autor, nascidas no seio das lutas consiliares portuguesas no processo da revolução dos Cravos, são de grande atualidade, não só por reporem as possibilidades da agenda conselhista aos atuais movimentos sociais anti-capitalistas, como também por oxigenarem a necessidade do permanente debate teórico no seio das várias tradições marxistas brasileiras e portuguesas.

26 marxismo heterodoxo de João Bernardo 